

\begin{tabular}{|c|c|c|c|c|c|c|}
\hline 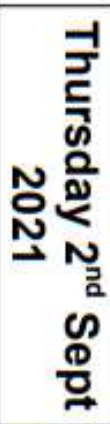 & & 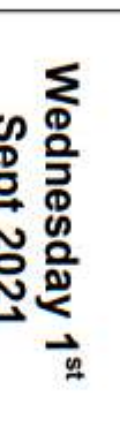 & 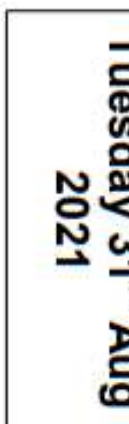 & & 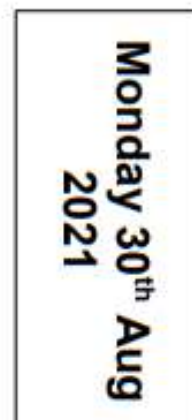 & \\
\hline 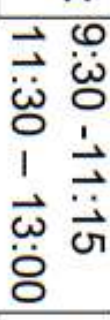 & $\begin{array}{l}\vec{u} \\
\dot{8} \\
1 \\
\overrightarrow{0} \\
\overrightarrow{\vec{v}}\end{array}$ & 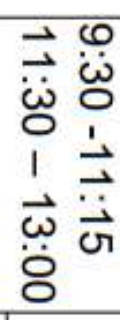 & 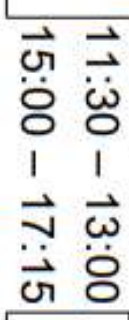 & $\begin{array}{l}\stackrel{\varphi}{\dot{\omega}} \\
\text { ’ } \\
\dot{\vec{े}} \\
\dot{\vec{v}}\end{array}$ & 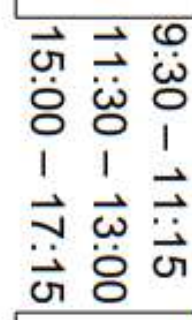 & $\begin{array}{l}\frac{0}{0} \\
\frac{\sigma}{0} \\
\frac{\pi}{\hat{i}}\end{array}$ \\
\hline 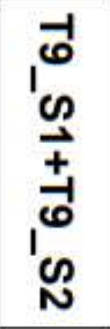 & $\begin{array}{l}\exists \\
1 \\
1\end{array}$ & ' & 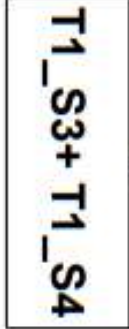 & $\begin{array}{l}-1 \\
\stackrel{1}{\prime} \\
N\end{array}$ & 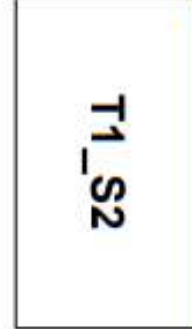 & 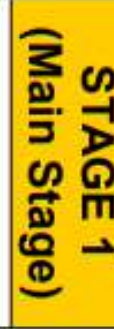 \\
\hline
\end{tabular}
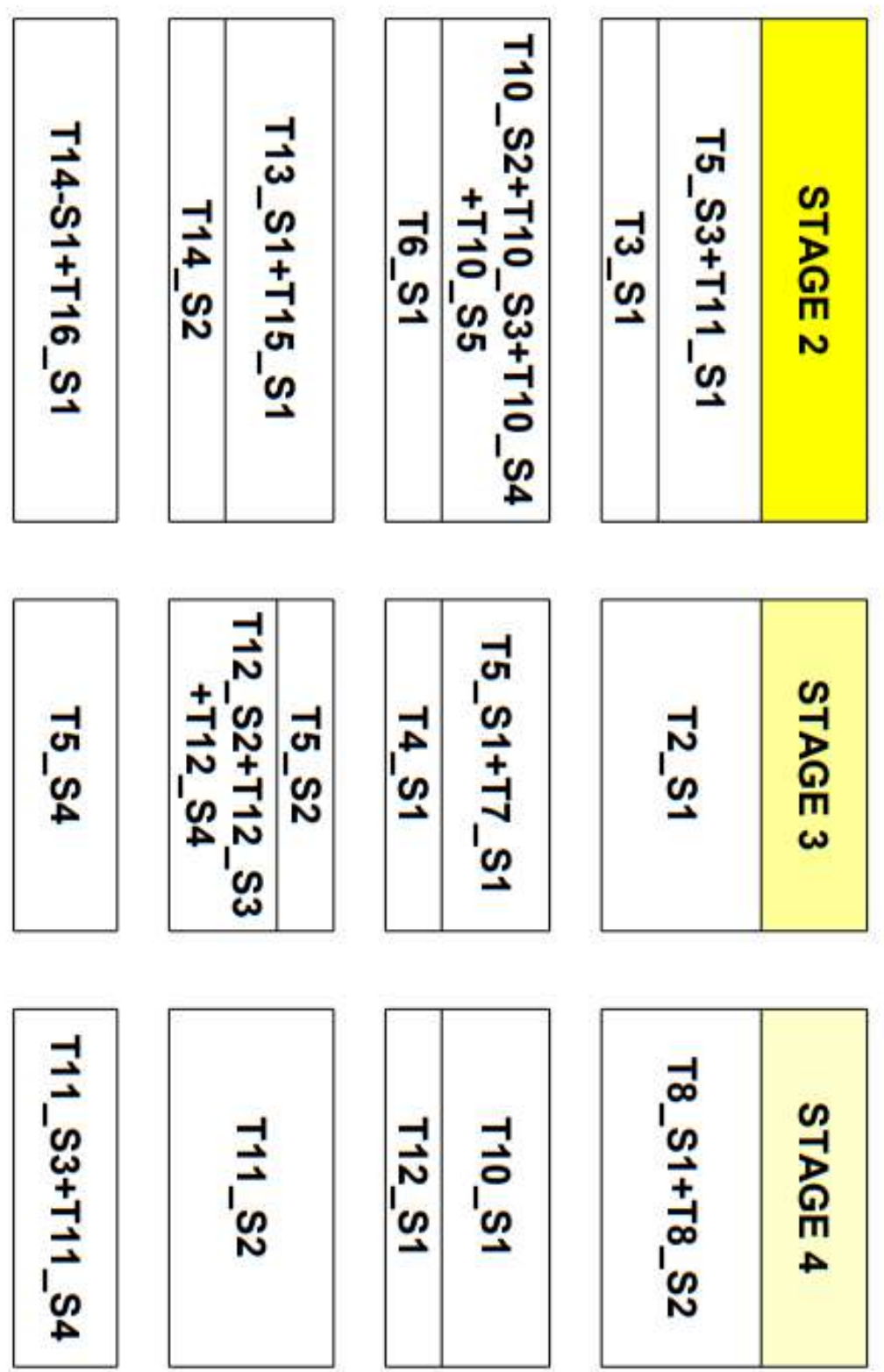

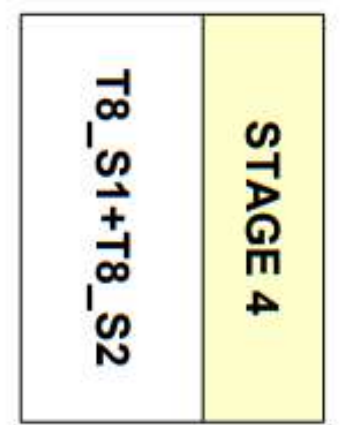




\section{Mineralogy in the modern world}

Following the success of the 1st and 2nd European Mineralogical Conference, the emc2020 will be focused on current and future challenges in the Earth, planetary and environmental sciences, and fostering an exchange of new views and research results between scientists from Europe and beyond.

The city of Kraków is a vibrant, academic and tourist city in the heart of Europe. Modern infrastructure, efficient public transportation and famous Polish hospitality make it a safe and friendly place for visitors from all over the world. The city dates back to Middle Ages and has traditionally been one of the leading centers of Polish and European academic, cultural, and artistic life. It was the capital of Poland from 1038 to 1569.

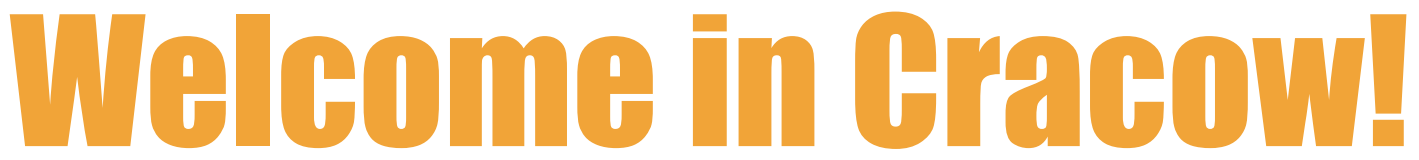

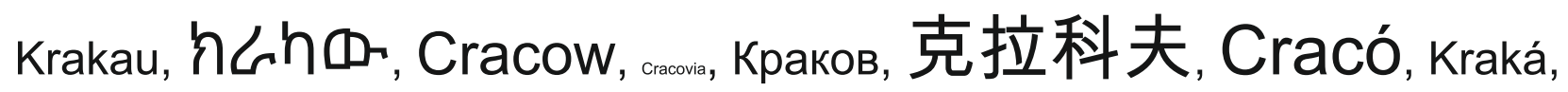
クラクフ, كراكوف, Cracovie, Krakov, Краків, Cra-cốp, Krakovja

\section{Scientific Committee}

Tomasz Bajda (Chair, PTMin], Marc Blanchard [SFMC), Gerhard Brey [DMG],

Piergiulio Gappelletti [SIMP],

Giuseppe Gruciani [SIMP], Jose Fernandez-Barrenechea [SEM], Reinhard Fischer [DMG], Tapio Halkoaho [MinSocFin], Heidi Höfer (DMG),

Sergey V. Krivovichev [RMS], Maciej Manecki [PTMin], Frank Melcher [ÖMG], Kevin Murphy [MinSoc], Ewa Staby [EMU]

Organizing Committee

Tomasz Bajda,

Anna Inglot,

Jakub Kierczak,

Krzysztof Szopa,

Justyna Topolska

Marta Polak 
The EMC2020 is organized by the PTMin [Mineralogical Society of Poland] on behalf of other European mineralogical societies:

DMG-Deutsche Mineralogische Gesellschafit MinSoc - Mineralogical Society of Great Britain \& Ireland

MinSocFin - Mineralogical Society of Finland ÖMG - österreïchische Mineralogische Gesellschafit RMS - Russian Mineralogical Society SEM-Sociedad Española de Mineralogía SFMC-Société Françaìse de Minéralogie et de Gristallographie

SIMP - Societa' Italiana di Mineralogia e Petrologia SSMP - Swiss Society of Mineralogy and Petrology

\section{with participation of:}

\section{EMU - European Mineralogical Union}

ING PAN - Institute of Geological Sciences, Polish Academy of Sciences Geo8 - GFz German Research Centre for Geosciences
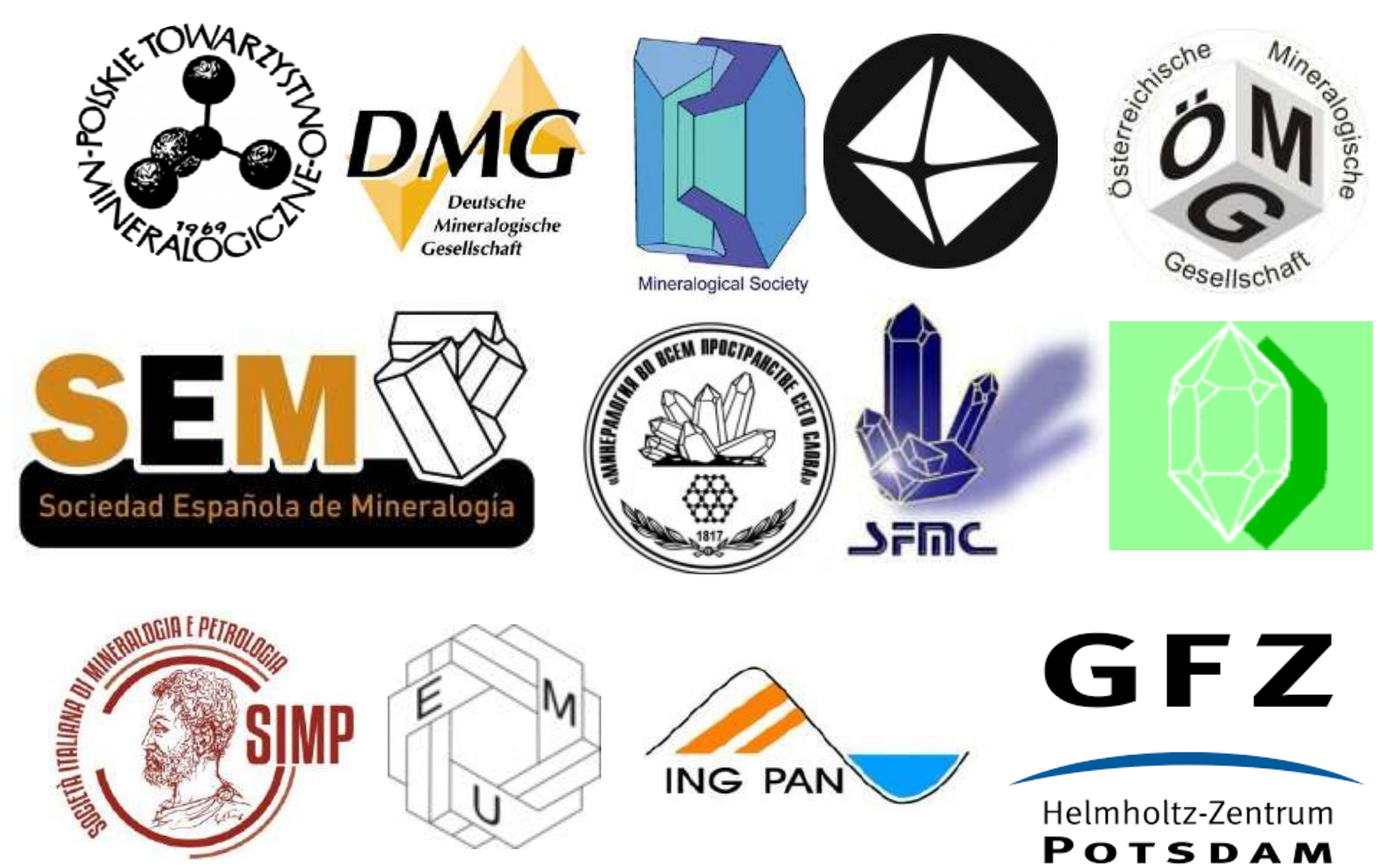


\title{
Plenary Lecture THE EFFECT OF PRESSURE ON OPEN-FRAMEWORK SILICATES: ELASTIC BEHAVIOUR AND CRYSTAL-FLUID INTERACTION
}

Gatta G. Diego ${ }^{1}$

\author{
${ }^{1}$ Dipartimento di Scienze della Terra, Università degli Studi di Milano, Via Botticelli 23, 20133 Milan, Italy
}

The physical behavior of microporous materials (i.e., materials with structural voids $\leq 2 \mathrm{~nm}$ ) compressed in a fluid is strongly affected by the potential crystal-fluid interaction, with a penetration of new molecular species through the structural cavities in response to the applied pressure.

Recent experimental findings and computational modeling show that, when no crystal-fluid interaction occurs, the effects of pressure are mainly accommodated by tilting of the (quasi-rigid) tetrahedra, around the bridging oxygen atoms that act as hinges. Tilting of tetrahedra is the dominant mechanism at low-mid $P$-regime, followed by distortion and compression of polyhedra which become dominant at the mid-high $P$-regime. The mechanisms of deformation, accommodating the bulk compression, are governed by the topology of the tetrahedral framework. One of the most common deformation mechanisms in zeolitic frameworks is the increase of channels ellipticity. However, the compressibility of the cavities (in the form of channels or cages) is governed by the ionic and molecular extraframework content, with different unit-cell volume compressibility in isotypic structures.

Only a few zeolites experience a $P$-induced intrusion of new monoatomic species or molecules from the $P$ transmitting fluids. Natural zeolites, in particular, have well-stuffed channels at room conditions, which tend to hinder the penetration of new species through the structural cavities. A comparative analysis of experimental findings allow us to provide an overview of the intrusion phenomena, which are diverse for monoatomic species (e.g., $\mathrm{He}, \mathrm{Ar}, \mathrm{Kr}$ ), small (e.g., $\mathrm{H}_{2} \mathrm{O}, \mathrm{CO}_{2}$ ) or complex molecules, along with the recently observed $P$-induced polymerization phenomena (e.g., $\mathrm{C}_{2} \mathrm{H}_{2}, \mathrm{C}_{2} \mathrm{H}_{4}, \mathrm{C}_{2} \mathrm{H}_{6} \mathrm{O}, \mathrm{C}_{2} \mathrm{H}_{6} \mathrm{O}_{2}, \mathrm{BNH}_{6}$, electrolytic $\mathrm{MgCl}_{2} \cdot 21 \mathrm{H}_{2} \mathrm{O}$ solution), with potential technological and geological implications. Several variables control the sorption phenomena at high pressure: the "free diameters" of the framework cavities, nature and bonding configuration of the extra-framework population, the kinetic diameter of the potentially penetrating molecules, the partial pressure of the penetrating molecule in the fluid (if mixed with other non-penetrating molecules), the rate of $P$-increase, the surface/volume ratio of the crystallites under investigations, and the temperature at which the experiment is conducted. 